\title{
MODEL PEMBELAJARAN KALIMAT MENGGUNAKAN PENDEKATAN KOOPERATIF BERBASIS KARAKTER DI IKIP SILIWANGI-BANDUNG
}

\author{
Rochmat Tri Sudrajat $^{1}$, Woro Wuryani ${ }^{2}$ \\ 1,2 IKIP Siliwangi \\ ${ }^{1}$ rochmattrisudrajat@ikipsiliwangi.ac.id, ${ }^{2}$ woro-wuryani@ikipsiliwangi.ac.id
}

\begin{abstract}
This research entitled Model of Learning Sentence Using Character Based Co-operative Approach at IKIP Siliwangi Bandung. Learning is a system, which consists of various components that are interconnected with each other. These components include: objectives, materials, methods, and evaluations. The four components must be considered by teachers in choosing and determining learning models that will be used in learning activities. To improve the learning result of the language is needed an innovative effort that can remove or eliminate the obstacle mentioned above hence the researcher intend to arrange model of learning as alternative and solution in facing the problem of learning Indonesian language, specially in sentence material. In addition, the model is character-based to further enhance the ethics or values prevailing in the community. The model will be the researcher is a model of learning by using a character-based cooperative approach. This study aims to: Explain the condition of learning sentences in IKIP Siliwangi, describe the implementation of learning models that can improve the theory and application of student sentences IKIP Siliwangi, knowing the effectiveness of learning models.
\end{abstract}

Keywords: Sentence learning, cooperative approach, character based

\begin{abstract}
Abstrak
Penelitian ini berjudul Model Pembelajaran Kalimat Menggunakan Pendekatan Kooperatif Berbasis Karakter di IKIP Siliwangi Bandung. Pembelajaran merupakan suatu sistem, yang terdiri atas berbagai komponen yang saling berhubungan satu dengan lainnya. Komponen tersebut meliputi: tujuan, materi, metode, dan evaluasi. Keempat komponen tersebut harus diperhatikan oleh guru dalam memilih dan menentukan model-model pembelajaran yang akan digunakan dalam kegiatan pembelajaran. Untuk meningkatkan hasil pembelajaran berbahasa diperlukan adanya usaha yang inovatif yang dapat menghapus atau menghilangkan kendala yang telah disebutkan di atas maka peneliti berniat untuk menyusun model pembelajaran sebagai alternatif dan solusi dalam menghadapi masalah-masalah pembelajaran bahasa Indonesia, khususnya dalam materi kalimat. Selain itu, model ini berbasis karakter untuk lebih meningkatkan pula etika atau nilai-nilai yang berlaku di masyarakat. Adapun model yang akan peneliti adalah Model pembelajaran dengan menggunakan pendekatan kooperatif berbasis karakter. Penelitian ini bertujuan untuk: Memaparkan kondisi pembelajaran kalimat di IKIP Siliwangi, mendeskripsikan implementasi model pembelajaran yang dapat meningkatkan pemehaman teori dan aplikasi kalimat mahasiswa IKIP Siliwangi, mengetahui keefektifan model pembelajaran.
\end{abstract}

Kata Kunci: Pembelajaran kalimat, pendekatan kooperatif, berbasis karakter. 


\section{PENDAHULUAN}

Belajar pada hakikatnya adalah interaksi pada semua situasi yang ada di sekitar individu. Belajar dapat dipandang sebagai proses yang dikendalikan oleh tujuan dan proses perbuatan melalui pengalaman. Pelaku proses belajar adalah guru dan siswa. Perilaku kedua pelaku berkaitan, yang pertama adalah mengajar dan perilaku yang kedua adalah belajar. Dua perilaku ini, berkaitan dengan bahan pem-belajaran. Bahan pembelajaran dapat berupa pengetahuan, nilai-nilai, seni, agama, sikap dan keterampilan.

Pembelajaran merupakan suatu sistem, yang terdiri atas berbagai komponen yang saling berhubungan satu dengan lainnya. Komponen tersebut meliputi: tujuan, materi, metode, dan evaluasi. Keempat komponen tersebut harus diperhati-kan oleh guru dalam memilih dan menentukan model-model pem-belajaran yang akan digunakan dalam kegiatan pembelajaran. Sekolah sebagai rumah dalam melaksanakan pembelajaran formal mempunyai tanggung jawab untuk membina dan memupuk ke-terampilan siswa dalam berbahasa. Kurikulum bahasa Indonesia mencantumkan hakikat pembelajaran bahasa Indonesia adalah belajar berkomunikasi (Puskur, 2003). Oleh karena itu, pembelajaran bahasa Indonesia diarahkan untuk meningkatkan kemampuan siswa dalam berkomunikasi baik lisan maupun tulisan. Di sekolah-sekolah, pembelajaran bahasa belum memuas-kan. Salah satu masalah pemicu lemahnya pembelajaran bahasa adalah penggunaan metode. Cara penyampaian guru cenderung kurang bervariasi (Tarigan, 1986: 39) Padahal, cara guru mengajar sangat mempengaruhi cara siswa belajar. Adapun model yang akan peneliti adalah Model pembelajaran dengan menggunakan pendekatan kooperatif berbasis karakter.

Pembahasan rencana penelitian ini adalah pengembangan model pembelajaran Kalimat dengan menggunakan pendekatan kooperatif berbasis karakter pada mahasiswa IKIP Siliwangi. Tujuannya adalah menguji keefektifan model tersebut dan mengaji perbedaan yang signifikan tentang kemampuan menguasai teori dan aplikasi penggunaan kalimat sebelum dan sesudah pener apan model tersebut serta mendeskripsikan langkah-langkah pembelajarannya.

\section{KAJIAN TEORI DAN METODE}

\section{Metode Pembelajaran}

Model pembelajaran merupakan suatu sarana yang dipilih oleh guru untuk menyampaikan pelajaran, dengan memberikan pengalaman tertentu, sehingga siswa dapat menangkap kesan yang lebih memudahkan tentang ini pelajaran yang diberikan. Model pembelajaran yang dipilih oleh seorang guru dalam usaha mengefektifkan pengajar dapat ditentukan berdasarkan kondisi- 
kondisi tertentu yang berkenaan dengan situasi kelas sarana dengan tersedia, alokasi waktu dan kandungan mated pelajaran yang akan disajikan. Model pembelajaran bahasa Indonesia terdiri dari: Model pembelajaran membaca, model pembelajaran menyimak, model pembelajaran berbicara, dan model pem-belajaran menulis.

\section{Menulis}

Menulis adalah merupa-kan kegiatan yang dilakukan manusia dalam kehidupan sehari-hari. Dengan menulis orang dapat melakukan komunikasi secara mudah dan efektif. Dengan menulis orang dapat mendokumenkan sesuatu agar mudah diingatnya. Kete-rampilan menulis adalah kemampuan seseorang dalam melukrskan lambang graphis yang dimengerti oleh penulis bahasa itu sendiri maupun orang lain yang mempunyai kesamaan pengertian terhadap simbol-simbol habasa tersebut (Suriamiharja, 1996: 2). Tujuan menulis merupakan penentu yang pokok dan akan mengarahkan serta membatasi karangan. Kesadaran mengenai tujuan selama proses penulisan akan menjaga keutuhan tulisan.

Hartig (dalam Tarigan 1983:24-25) mengatakan bahwa tujuan kegiatan menulis ada tujuh, assigment purpose (tujuan penugasan), altruistic purpose (tujuan altruistik), persuasive purpose (tujuan persuatif), informational purpose (tujuan informational/tujuan penerangan), self-expresive purpose (tujuan pernyataan diri), creative purpose (tujuan kreatif), problemsolving purpose (tujuan pemecahan masalah).

Tujuan penugasan (assigment purpose) yaitu penulis melakukan kegiatan menulis karena adanya tugas, bukan atas kemauan sendiri. Tujuan altruistik (altruistic purpose) yaitu menulis untuk menyenangkan para pembaca, menghindarkan kedukaan para pembaca, ingin menolong para pembaca memahami, meng-hargai perasaan dan penalaran-nya, ingin membuat hidup para pembaca lebih mudah dan lebih menyenangkan dengan karyanya itu. Tujuan persuasive (persuasive purpose) yaitu tulisan yang bertujuan meyakin-kan para pembaca akan kebenaran gagasan yang diutarakan. Tujuan informasional atau penerangan (informational purpose) yaitu tulisan yang bertujuan memberi informasi atau keterangan atau penerangan kepada para pembaca yang berupa paparan atau deskripsi. Tujuan pernyataan diri (self-expresive purpose) yaitu tulisan yang bertujuan memperkenalkan atau menyatakan diri sang pengarang kepada para pembaca. Tujuan kreatif (creative purpose) yaitu tujuan yang erat berhubungan dengan tujuan pernyataan diri. Tujuan pemecahan masalah (problem-solving purpose) yaitu dengan tulisan ini sang penulis ingin memecahkan masalah yang dihadapi. 
Dari pendapat di atas dapat disimpulkan bahwa tujuan menulis adalah memberikan informasi atau keterangan kepada pembaca, meyakinkan para pembaca akan kebenaran gagasan yang diutarakan dan mengarahkan serta membatasi tulisan sehingga akan menghasilkan suatu tulisan yang utuh.

\section{Kalimat}

Kalimat adalah bagian terkecil ujaran atau teks yang megungkapkan pikiran yang utuh secara keterbatasan. Dalam wujud tulisan, diawali dengan huruf kapital dan diakhiri dengan tanda baca yaitu dengan tanda titik, tanda tanya, dan tanda seru. Dalam wujud lisan, diiringi oleh alunan titi nada, disela oleh jeda diakhiri oleh intonasi selesai.

\section{PEMBELAJARAN KOOPERATIF}

Menurut Kauchak dan Eggen (dalam Utiya Azizah, 1998: 17) pembelajaran kooperatif merupakan strategi pembelajaran yang melibat-kan siswa untuk bekerja secara kolaboratif dalam mencapai tujuan. Sedangkan Slavin (1994: 287) menyatakan bahwa dalam pembelajaran kooperatif siswa bekerja sama dalam kelompok kecil saling membantu untuk mempelajari suatu materi.

Berdasarkan pendapat para ahli di atas pembelajaran kooperatif merupakan suatu strategi pembelajaran tempat siswa belajar dalam kelompok kecil yang terdiri dari 4-5 siswa dengan tingkat kemampuan yang berbeda.

Tujuan pembelajaran kooperatif adalah menciptakan situasi keberhasilan individu yang ditentukan untuk mempengaruhi keberhasilan individu yang ditentu-kan untuk mempengaruhi keber-hasilan kelompoknya (Slavin, 1995),

\section{PENDIDIKAN KARAKTER}

Menurut Doni Koesoema A. mengartikan pendidikan sebagai proses internalisasi budaya ke dalam diri individu dan masyarakat menjadi beradab. Ada pula yang mendefinisi-kan pendidikan sebagai proses dimana sebuah bangsa mem-persiapkan generasi mudanya untuk menjalankan kehidupan, dan untuk memenuhi tujuan hidup secara efektif dan efisien (Koesoema, 2007: 80).

Menurut Sudirman N. pendidikan adalah usaha yang dijalankan oleh seseorang atau sekelompok orang untuk mem-pengaruhi seseorang atau se-kelompok orang lain agar menjadi 
dewasa atau mencapai tingkat hidup dan penghidupan yang lebih tinggi dalam arti mantap (Sudirman, 1987: 4).

Menurut para ahli psikolog, beberapa nilai karakter dasar tersebut adalah: cinta kepada Allah dan ciptaan-Nya (alam dengan isinya), tanggung jawab, jujur, hormat dan santun, kasih sayang, peduli, dan kerjasama, percaya diri, kreatif, kerja keras, dan pantang menyerah, keadilan dan kepemimpinan; baik dan rendah hati, toleransi, cinta damai, dan cinta persatuan.

\section{METODE PENELITIAN}

Dalam suatu penelitian perlu menetapkan suatu metode yang sesuai dan dapat membantu meng-ungkapkan suatu permasalahan. Metode merupakan cara atau jalan yang ditempuh untuk mencapai tujuan. Tujuan penelitian adalah untuk mengungkapkan, meng-gambarkan, dan menyimpulkan hasil pemecahan masalah melalui cara tertentu sesuai dengan prosedur penelitian.

Langkah-langkah penelitian eksperimen ini yaitu sebagai berikut:

1. Pelaksanaan pre-test, yaitu suatu tes menulis kalimat yang diberikan kepada mahasiswa secara tertulis sebelum pe-laksanaan perkuliahan.

2. Pemberian perlakuan dengan menggunakan model koperatif berbasis karakter

3. Post-tes, merupakan bentuk tes akhir yang diberikan setelah perkuliahan telah disampaikan yaituuntuk mengetahui ke-efektivitan dari perlakuan.

\section{HASIL PENELITIAN}

\section{Hasil Penelitian}

\section{Hasil Pretest}

Dari hasil penelitian menggambarkan persentase keseluruhan hasil menulis kalimat mahasiswa tanpa menggunakan kata acak. Dari data tersebut dapat dijelaskan hasilnya: 10 orang atau 25\% mendapat nilai amat baik, 22 orang atau 55\% mendapat nilai baik, 8 orang atau $20 \%$ mendapat nilai cukup.

\section{Hasil Postes}

Dari hasil penelitian menggambarkan presentase keseluruhan hasil tulisan mahasiswa dengan pem-belajaran kooperatif berbasis karakter. Dari data tersebut dapat dijelaskan hasilnya: 12 
orang atau 30\% mendapat nilai dengan kategori istimewa, 11 orang atau 27,5\% mendapat nilai dengan kategori amat baik, 14 orang atau 35\% mendapat nilai dengan kategori baik, 3 orang atau 7,5\% mendapat nilai dengan kategori cukup. Dengan demikian nilai karangan kedua ini sebagian terbesar masih tetap baik, namun yang mendapat nilai dengan kategori istimewa dan amat baik meningkat.

Berdasarkan hasil penelitian di atas terbukti bahwa pembelajaran menulis kalimat dengan meng-gunakan model kooperatif berbasis karakter mencapai nilai rata-rata 7,6. Nilai tersebut termasuk kategori amat baik.

Hasil pengamatan-pengamatan mengenai tingkah laku mahasiswa selama kegiatan menulis kalimat. Hasil pengamatan tersebut dicatat untuk menggambarkan proses per-kuliahan yang sedang berlangsung, sebagai berikut:

1. Mahasiswa kelihatan lebih berkonsentrasi ketika menulis kalimat melalui pembelajaran kooperatif

2. Kondisi kelas lebih tertib ketika perkuliahan me-nulis kalimat dengan menggunakan model kooperatif berbasis karakter.

3. Waktu penyelesaian menulis kalimat lebih cepat dengan menerapkan model kooperatif berbasis karakter.

Dari uraian di atas penulis menyimpulkan bahwa model menulis kalimat dengan menggunakan model kooperatif acak efektif dan me-nyenangkan bagi para mahasiswa.

\section{KESIMPULAN}

\section{A. Simpulan}

Berdasarkan hasil pe-nelitian yang telah dilaksanakan, maka penulis dapat mengambil beberapa kesimpulan sesuai dengan tujuan penelitian. Kesimpulan yang dimaksud penulis adalah sebagai berikut:

1. Pembelajaran menulis kalimat pada mahasiswa prodi Pendidikan Bahasa Indonesia di IKIP Siliwangi pada dasarnya sudah berlangsung dengan baik, baik dari sisi perangkat pembelajaran, maupun dari sisi proses serta evaluasinya. Namun demikian, pembelajaran yang sudah berlangsung baik tersebut dirasa baru menyentuk aspek kognitif mahasiswa saja, namun belum menyentuh pendalaman karakter mahasiswa yang tercermin melalui tulisan yang disusun oleh mahasiswa.

2. Implementasi model pem-belajaran kooperatif berbasis karakter dapat meningkatkan proses pemrkuliahan materi penulisan kalimat pada mahasiswa prodi Pendidikan 
Bahasa Indonesia IKIP Siliwangi Bandung. Hal tersebut dapat ditunjukkan dengan aktivitas mahasiswa yang relatif tinggi, hal ini karena dipengaruhi oleh kegiatan perkuliahan model kooperatif yang dilaksana-kan. Model kooperatif menuntut mahasiswa ber-kerja sama merumuskan masalah, memecahkan masalah secara bersama serta menghasilkan produk (tulisan) hasil pemikiran bersama.

3. Model pembelajaran koopeartif berbasis karakter dalam perkuliahan materi menulis telah terbukti dapat meningkatkan kemampuan siswa dalam menulis kalimat baik dari sisi kualitas maupun kuantitas. Tulisan yang disusun mahasiswa terdapat nilai-nilai karakter yang tercermin dari tulisan itu. Dari sekian banyak nilai karakter yang ditunjukkan oleh mahasiswa pada umumnya menunjukkan karakter yang sifatnya individu, seperti jujur, disiplin, kerja keras, kreatif, mandiri yang yang lainnya.

\section{B. Saran}

Setelah menganalisis hasil penelitian, penulis mengemukakan saran sebagai berikut.

1. Bagi Dosen

Model pembelajaran kooperatif berbasis karakter bisa digunakan sebagai salah satu alternatif model pembelajaran menulis kalimat pada mahasiswa karena model ini sudah terbukti efektif penerapannya.

2. Bagi Mahasiswa

Mahasiswa hendaknya lebih melakukan penekanan ter-hadap integrasi nilai-nilai karakter pada tulisan-tulisan yang dibuat baik dalam hal karangan, makalah, artikel, dan tulisan-tulisan lainnya. Mahasiswa bisa menggunakan model kooperatif sebagai salah satu model perkuliahan yang efektif untuk perkuliahan materi menulis kalimat.

3. Peneliti selanjutnya

Calon peneliti bisa mencermati gagasan-gagasan dan temuan yang terdapat dalam penelitian ini sebagai bahan untuk penelitian selanjutnya.

\section{REFERENCES}

A Marimba, 1989, Pengantar Filsafat Pendidikan Islam, Bandung: PT. AL-. Ma'arif. 

Berbasis Karakter di Ikip Siliwangi-Bandung

A, Doni Koesoema, Pendidikan Karakter, Strategi Mendidik Anak di. Zaman Global, Jakarta: Grasindo, 2007

Abdul Majid, Dian Andayani, 2010, Pendidikan karakter dalam Perspektif Islam. Bandung: Insan Cita Utama

Agus Suriamiharja, dkk. 1996. Petunjuk Praktis Menulis. Jakarta: Departemen

Akhadiah, Sabarti dkk.1988. Pembinaan Kemampuan Menulis Bahasa Indonesia. Jakarta: Erlangga

Arends 1997. Model-Model Pembelajaran Inovatif berorientasi Konstuktivitis,. Jakarta: Prestasi Pustaka Publisher

Arikunto, S. (2013). Prosedur Penelitian: Suatu Pendekatan Praktik. Jakarta: Rineka Cipta

Depdiknas. 2003. Kurikulum 2004 Standart Kompetensi. Jakarta: Puskur.

Dharma Kesuma, et.al, 2011, Pendidikan Karakter Kajian Teori dan Praktik di Sekolah, Bandung: Remaja Rosdakarya

Doni Koesoema A. 2007, Pendidikan Karakter: Strategi Mendidik Anak di Zaman Modern. Jakarta: Grasindo

Gunawan,Heri. 2012. Pendidikan Karakter Konsep dan Implementasi. Bandung: Alfabeta.

Guntur Tarigan, Henry. 1986. Menyimak Sebagai Suatu Keterampilan Berbahasa. Angkasa Bandung.

Ibrahim, Muslimin, dkk. 2000. Pembelajaran Kooperatif. Surabaya: UNESA Press

Megawangi, Ratna. 2004. Pendidikan Karakter Solusi yang Tepat untuk. Membangun Bangsa. Jakarta: BPMIGAS

Samosir, Aldon. (2007). Pengertian Keterampilan Berbicara dalam a-research.upi.edu/

Slavin, Robert E. (2009). Cooperatif Learning Teori Riset dan Praktek. Bandung: Nusa Media.

Sudirman N, 1987, Ilmu Pendidikan, Bandung:Remaja Rosdakarya 